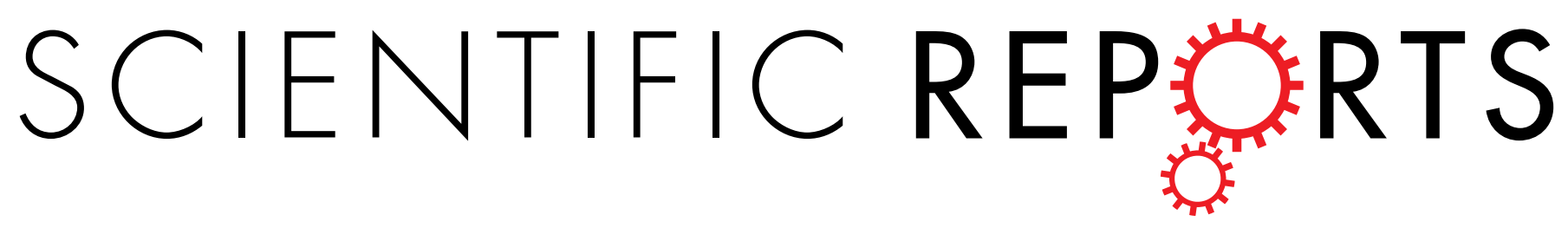

\title{
OPEN Erratum: The structure of Legionella pneumophila LegK4 type four secretion system (T4SS) effector reveals a novel dimeric eukaryotic- like kinase
}

Ali Flayhan, Célia Bergé, Nathalie Baïlo, Patricia Doublet, Richard Bayliss \& Laurent Terradot

Scientific Reports 5:14602; doi: 10.1038/srep14602; published online 30 September 2015; updated on 03 February 2016

In the original version of this Article, Laurent Terradot was incorrectly listed as being affiliated with 'Department of Biochemistry, University of Leicester, Leicester LE1 9HN, United Kingdom'. The correct affiliation is listed below:

UMR 5086 BMSSI CNRS-Université de Lyon, Institut de Biologie et Chimie des Protéines, 7 Passage du Vercors, F-69367 Lyon Cedex 07, France

This error has now been corrected in the PDF and HTML versions of the Article.

(c) (i) This work is licensed under a Creative Commons Attribution 4.0 International License. The images or other third party material in this article are included in the article's Creative Commons license, unless indicated otherwise in the credit line; if the material is not included under the Creative Commons license, users will need to obtain permission from the license holder to reproduce the material. To view a copy of this license, visit http://creativecommons.org/licenses/by/4.0/ 